\title{
Elaboração de bebida láctea fermentada com diferentes tipos de polpas de frutas
}

\author{
Geruza Pereira da Cruz ${ }^{1}$, Flávia Rosana dos Santos Rocha ${ }^{2}$, Katyane Benquerer Oliveira de Assis ${ }^{3}$, Adriana \\ Benquerer Oliveira Palma ${ }^{4}$, Renata Ribeiro Durães ${ }^{5}$, Marinilza Soares Mota Sales ${ }^{6}$, Margarete Fernandes \\ Araújo $^{7}$, Delaine Martins da Silva ${ }^{8}$, João Adilson Nunes Oliveira ${ }^{9}$, Paula Karoline Soares Farias ${ }^{10}$
}

DOI: https://doi.org/10.35699/2447-6218.2020.18137

\begin{abstract}
Resumo
Neste estudo desenvolveram-se diferentes tipos de bebidas lácteas e verificar a aceitabilidade entre os acadêmicos e funcionários de uma faculdade particular. Foram preparados quatro tipos de bebidas lácteas fermentadas contendo quatro sabores diferentes de polpas de frutas: seriguela, coquinho azedo, goiaba e maracujá. Foram realizadas analises microbiológicas avaliando-se a presença de Salmonella sp. e enumeração de coliformes totais e termotolerantes. Foram realizados teste de aceitabilidade e intenção de compra das bebidas produzidas. Para comparar os resultados obtidos entre as bebidas com diferentes tipos de polpas de frutas do cerrado foram elaborados gráficos descritivos. Em relação aos parâmetros microbiológicos, a contagem de microrganismos indicadores encontrava-se dentro dos padrões estabelecidos pela legislação brasileira. A análise sensorial foi realizada com 200 provadores. A bebida láctea fermentada no sabor de coquinho-azedo apresentou a melhor aceitação dentro as quatro ofertadas com 43,5\%. De forma geral houve boa intenção de compra entre todos os produtos avaliados. Espera-se que este alimento traga benefícios tecnológicos e nutricionais a partir de constituintes nutritivos e de baixo custo.
\end{abstract}

Palavras-chave: Frutas. Produtos Fermentados do Leite. Soro de Leite.

\section{Elaboration of fermented milk drink with different types of fruit pulp}

Abstract

In this study different types of dairy drinks were developed and the acceptability among academics and employees of a private college was verified. Four types of fermented dairy beverages containing four different flavors of fruit pulp

${ }^{1}$ Faculdades Integradas do Norte de Minas - FUNORTE. Montes Claros, MG. Brasil. https://orcid.org/0000-0002-2181-5036

${ }^{2}$ Faculdades Integradas do Norte de Minas - FUNORTE. Montes Claros, MG. Brasil. https://orcid.org/0000-0001-5577-1070

${ }^{3}$ Universidade Estadual de Montes Claros - Unimontes. Montes Claros, MG. Brasil. https://orcid.org/0000-0001-6178-2219

${ }^{4}$ Universidade Estadual de Montes Claros - Unimontes. Montes Claros, MG. Brasil. https://orcid.org/0000-0002-0567-3285

${ }^{5}$ Faculdades Integradas do Norte de Minas - FUNORTE. Montes Claros, MG. Brasil. https://orcid.org/0000-0002-0871-146X

${ }^{6}$ Universidade Estadual de Montes Claros - Unimontes. Montes Claros, MG. Brasil. https://orcid.org/0000-0002-4987-3879

${ }^{7}$ Faculdades Integradas do Norte de Minas - FUNORTE. Montes Claros, MG. Brasil. https://orcid.org/0000-0001-8626-4581

${ }^{8}$ Faculdades Integradas do Norte de Minas - FUNORTE. Montes Claros, MG. Brasil. https://orcid.org/0000-0001-8030-5370

${ }^{9}$ Universidade Estadual de Montes Claros - Unimontes. Montes Claros, MG. Brasil. https://orcid.org/0000-0002-3478-3491

${ }^{10}$ Universidade Estadual de Montes Claros - Unimontes. Montes Claros, MG. Brasil. https://orcid.org/0000-0003-2967-5469

*Autor para correspondência: paulak.soares@hotmail.com

Recebido para publicação em 24 de janeiro de 2020. Aceito para publicação 25 de Dezembro de 2020. e-ISSN: 2447-6218 / ISSN: 2447-6218. Atribuição CC BY. 
were prepared: seriguela, sour coconut, guava and passion fruit. Microbiological analyses were performed evaluating the presence of Salmonella sp. and enumeration of total coliforms and thermotolerants. Acceptability and purchase intention tests were performed for the beverages produced. To compare the results obtained among the beverages with different types of fruit pulp from the cerrado, descriptive graphs were prepared. Regarding microbiological parameters, the count of indicator microorganisms was within the standards established by Brazilian legislation. The sensory analysis was performed with 200 tasters. The milk beverage fermented in coconut-azed flavor presented the best acceptance within the four offered with $43.5 \%$. In general there was a good intention of purchase among all the products evaluated. This food is expected to bring technological and nutritional benefits from nutritious and low cost constituents.

Keyword: Fruit. Cultured Milk Products. Whey.

\section{Introdução}

O Brasil encontra-se na sexta posição na produção mundial de leite com 32,3 bilhões de litros e apresenta um crescimento de $3,07 \%$ da produção mundial em 2014, e na mesma posição entre os países que mais consomem leite fluído (Brasil, 2014). A região Sudeste é responsável por $41,4 \%$ da produção nacional, seguida pela região Sul com 33,8 \%, no Centro-Oeste verifica-se $14,7 \%$ e nas regiões Norte e Nordeste registra-se um percentual de 5,0\% cada um (IBGE, 2018). Observa-se uma nova tendência na área de laticínios com a produção e desenvolvimento de iogurtes e leites fermentados funcionais, devido sua alta aceitabilidade pelos consumidores, além de demonstrarem um sabor agradável e possuírem alto valor nutricional, são produtos que apresentam um grande potencial para o consumo de probióticos pela população (Kempka et al., 2008).

Para a formulação dos leites fermentados é realizada a utilização do soro de leite bovino, o qual é um subproduto importante para a indústria de laticínios e rico em componentes nutricionais (Oliveira; Bravo; Tonial, 2012). A utilização industrial desse subproduto tem contribuído para o aperfeiçoamento e desenvolvimento de novos produtos alimentícios, como bebidas lácteas fortificadas com micronutrientes presentes no soro do leite (Luiz et al., 2014). Detecta-se também outro interesse por parte das indústrias de alimentos tanto para humanos quanto para os animais, pois esse subproduto apresenta proteínas de alta qualidade biológica (Desconsi et al., 2014).

O soro do leite ainda é alvo de grande preocupação ambiental, sendo considerado um resíduo poluente, pelo descarte irregular realizado por muitas indústrias de laticínios, que mesmo com todas as características citadas acima desprezam esse subproduto que é tão rico nutricionalmente (Batista et al., 2015). No Brasil, considera-se a produção de bebidas lácteas como um dos principais métodos de aproveitamento do soro de leite fluido, entretanto percebe-se que apenas $15 \%$ do volume total é utilizado para este fim (Ferrari; Baldoni; Azeredo, 2013).

O cerrado brasileiro é um bioma que possui um grande número de espécies de frutos nativos, o que é potencialmente interessante para a indústria alimentar. A Butia capitata (coquinho azedo) é um fruto do cerrado brasileiro, considerado nutricionalmente rico em carotenoides, ácidos graxos, minerais, vitamina $\mathrm{C}$ e compostos fenólicos, e os frutos utilizados para produzir polpas, sucos, sorvetes e licores (Aguiar et al., 2014). A Passiflora edulis (maracujá) é uma planta de clima tropical, e o Brasil caracteriza-se como o maior produtor mundial, com uma produção de 838.244 toneladas/ano. O maracujá-amarelo, espécie tropical nativa, é muito utilizado para polpas e sucos (Storck et al., 2014).

A Spondias purpúrea (seriguela) é uma espécie de floração, pertencente à família Anacardiaceae, nativa de plantas tropicais da região da América (Arshadi et al., 2015), apresenta-se na cor verde para amarelo, laranja ou vermelho, e caracteriza-se por uma textura cremosa e suculenta, com sabor doce ou ácido, podendo ser consumidas maduras ou não, com ou sem a pele, crus, cozidos, secos, em sobremesas, como conservas ou como bebidas (Engels et al., 2012).

A Psidium guajava L. (goiaba), pertence à família Myrtaceae, é natural das regiões tropicais e subtropicais do mundo, os frutos são conhecidos por possuírem grandes quantidades de vitaminas e minerais e têm níveis elevados de antioxidantes. Pode ser classificadas como cultivares brancas e rosadas, além do fruto conter altas quantidades de açúcares fermentáveis tais como frutose, glicose, sacarose, pectina, minerais (cálcio e fósforo), antioxidantes (vitaminas A, B, C, E, niacina, licopeno, carotenóides, polifenóis) e fibras dietéticas elevadas (Flores et al., 2013). Diante disso, o objetivo deste estudo foi desenvolver diferentes tipos de bebidas lácteas e verificar a aceitabilidade entre os acadêmicos e funcionários de uma faculdade particular no Norte de Minas Gerais.

\section{Material e Métodos}

\section{Produção da bebida láctea fermentada com diferentes polpas de frutos do cerrado}

A produção da bebida láctea fermentada foi realizada no laboratório de Tecnologia de Alimentos do Instituto de Ciências Agrárias da Universidade Federal de 
Minas Gerais - ICA/UFMG, em Montes Claros, de acordo com metodologia de Farias (2016) com modificações. Foram preparados quatro tipos de bebidas lácteas fermentadas contendo quatro sabores diferentes de polpas de frutas: seriguela, coquinho azedo, goiaba e maracujá.

As bebidas elaboradas consistiram de leite integral UHT, soro de leite integral reconstituído, sacarose, amido modificado e a cultura láctica DVS termofílica, procedente da Christian Hansen do Brasil, contendo cepas mistas de Streptococcus thermophilus, Lactobacillus delbrueckii subsp. bulgaricus, em forma de grânulos liofilizados. Essa primeira mistura recebeu tratamento térmico $\left(45^{\circ} \mathrm{C}\right)$, e a cada 2 horas aferiu-se o $\mathrm{pH}$, até que a amostra atingisse o $\mathrm{pH}$ de 4,6 , quando foi colocada no resfriamento $\left(5^{\circ} \mathrm{C}\right)$.

Em seguida, fez-se agitação do coágulo e adicionou-se a polpa de fruta com posterior agitação manual para distribuir uniformemente. As bebidas foram então envasadas em embalagens plásticas de $50 \mathrm{~mL}$ fechadas hermeticamente, identificadas e armazenadas sob refrigeração $\left(5^{\circ} \mathrm{C}\right)$, durante o período de 14 dias. Todo o experimento foi realizado em triplicata.

\section{Análises microbiológicas}

As análises microbiológicas das bebidas lácteas fermentadas foram realizadas no laboratório de Sanidade Animal no Centro de Pesquisas em Ciências Agrárias CPCA do Instituto de Ciências Agrárias da Universidade Federal de Minas Gerais, em Montes Claros, segundo as recomendações descritas pela Instrução Normativa no 62 do Ministério da Agricultura Pecuária e Abastecimento, avaliando-se a presença de Salmonella sp. e enumeração de coliformes totais e termotolerantes (Brasil, 2003).

\section{Teste de aceitabilidade e Intenção de compra}

A análise sensorial foi realizada em faculdade privada de Montes Claros. Foram recrutados 200 provadores, dentre os acadêmicos e funcionários de ambos o sexo, com faixa etária entre 18 a 60 anos. Após serem selecionados, os participantes receberam os termos de Consentimento Livre e Esclarecido para que se conscientizassem da participação.

Foram apresentadas aos provadores quatro amostras de bebida láctea fermentada nos sabores de coquinho-azedo, goiaba, maracujá e seriguela para que fossem analisadas sensorialmente. Para este procedimento utilizou-se o Teste de Aceitação com escala hedônica de 9 pontos, (9-gostei extremamente, 8-gostei moderadamente, 7-gostei regularmente, 6-gostei ligeiramente, 5-não gostei, nem desgostei, 4-desgostei ligeiramente, 3-desgostei regularmente, 2-desgostei moderadamente, 1-desgostei extremamente) e o teste de intenção de compra (7-compraria sempre, 6-compraria muito frequentemente, 5-compraria frequentemente, 4-compraria ocasionalmente, 3-compraria raramente, 2-compraria muito raramente, 1-nunca compraria), conforme descrito pelo Instituto Adolfo Lutz (2008).

Para realização da análise sensorial foram servidas a cada provador $50 \mathrm{~mL}$ de cada bebida láctea fermentada em copos descartáveis brancos e sem identificação, para reduzir a influência de uma amostra sobre a outra. Foi oferecido aos provadores água em temperatura ambiente para limpeza do paladar entre a prova das amostras. Os testes foram aplicados individualmente evitando desta forma o contato dos participantes e também qualquer tipo de influência nos resultados. O trabalho foi aprovado pelo Comitê de Ética em Pesquisa da Associação Educativa do Brasil - SOEBRAS sob o no 2.216.184.

\section{Análise estatística dos resultados}

Todas as análises estatísticas foram feitas utilizando o software R. Para o Número mais provável (NMP) de coliformes totais e coliformes termotolerantes, estes foram baseados na legislação vigente (Brasil, 2007). Para comparar os resultados obtidos entre as bebidas com diferentes tipos de polpas de frutas do cerrado foram elaborados gráficos descritivos.

\section{Resultados e Discussão}

Os resultados obtidos com as análises microbiológicas atenderam ao recomendado pela legislação (Brasil, 2007) em todos os tratamentos em estudo durante todo o período de armazenamento estando os produtos aptos para o consumo, no que se refere ao padrão de identidade recomendado para bebida láctea fermentada.

Em relação aos parâmetros microbiológicos pode-se observar de acordo com a Tabela 1, que a contagem de microrganismos indicadores estão dentro dos padrões estabelecidos pela legislação brasileira, com valores máximos de $100 \mathrm{NMP} / \mathrm{mL}$ para coliformes totais e $10 \mathrm{NMP} / \mathrm{mL}$ para coliformes termotolerantes e ausência de Salmonella sp. nas bebidas lácteas fermentadas (Brasil, 2007).

De acordo com Baldissera et al. (2011), a aceitação do consumidor é um pré-requisito para que bebidas proteicas a base de soro tenham representação no preexistente mercado de bebidas lácteas. Ao analisar os dados dos gráficos apresentados pela figura 1, pode-se verificar que a bebida láctea fermentada no sabor de coquinho-azedo apresentou a melhor aceitação dentro das quatro ofertadas com 43,5\% (87 provadores), seguida da bebida láctea fermentada no sabor de maracujá que apresentou aceitação de 38,5\% (77 provadores).

As bebidas no sabor goiaba e seriguela obtiveram menor aceitação, sendo que a bebida láctea fermentada no sabor goiaba apresentou aceitação de 32,5\% (65 provadores), enquanto a bebida láctea fermentada no sabor de seriguela apresentou aceitação de 12,5\% (25 provadores). Associando aos efeitos benéficos das frutas e da ação dos microrganismos probióticos, o desenvolvi- 
mento de bebidas lácteas é baseado na possibilidade de

oferecer vantagens nutricionais adicionais ao consumidor (Siqueira et al., 2013).

Tabela 1 - Análises microbiológicas das bebidas lácteas fermentadas nos sabores goiaba, maracujá, seriguela e coquinho-azedo.

\begin{tabular}{lccc}
\hline $\begin{array}{l}\text { Bebida láctea } \\
\text { fermentada }\end{array}$ & $\begin{array}{c}\text { Coliformes Totais (NM- } \\
\text { P/g) }\end{array}$ & $\begin{array}{c}\text { Coliformes Fecais (NM- } \\
\text { P/g) }\end{array}$ & Salmonella SP. \\
\hline Coquinho-azedo & $<3$ & $<3$ & - \\
Goiaba & $<3$ & $<3$ & - \\
Maracujá & $<3$ & $<3$ & - \\
Seriguela & $<3$ & $<3$ & - \\
\hline
\end{tabular}

Figura 1 - Teste de aceitabilidade com as bebidas lácteas fermentadas nos sabores goiaba, maracujá, seriguela e coquinho-azedo. $(\mathrm{n}=200)$.

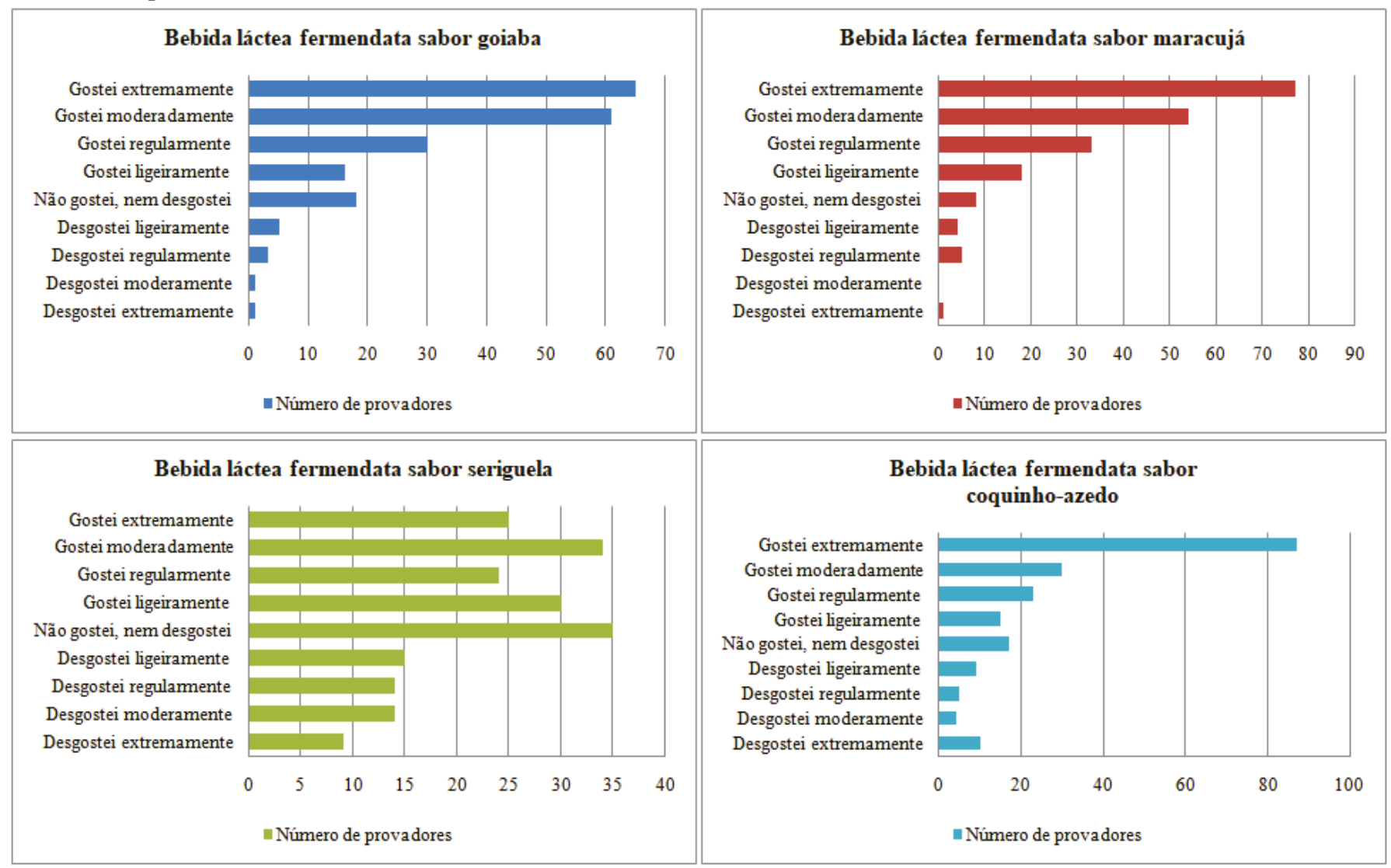

Fonte: próprios autores (2020).

Siqueira et al. (2015) avaliaram a aceitação sensorial de bebida láctea fermentada adicionada de diferentes concentrações de polpa de graviola. Os resultados demonstram que a bebida obteve boa aceitação, dados que estão de acordo com os obtidos no presente estudo. Em pesquisa com o objetivo avaliar o potencial comercial de uma bebida láctea probiótica de soro de queijo e polpa de açaí, Zoellner et al. (2009), verificou-se que o produto obtido foi bem aceito pelos avaliadores.

De acordo com os dados representados pelos gráficos da figura 2, observa-se que a bebida láctea fermentada no sabor de coquinho-azedo apresentou a me- lhor intenção de compra, com 44,5\% (89 provadores), seguida da bebida láctea fermentada no sabor de maracujá $41,5 \%$ (83 provadores), já as bebidas no sabor goiaba e seriguela foram menos aceitas pelo público, sendo que a bebida láctea fermentada no sabor goiaba apenas 37,5\% (75 provadores), e a no sabor de seriguela apenas $16,5 \%$ (33 provadores) comprariam a bebida. Ainda assim, de forma geral, houve boa intenção de compra entre todos os produtos avaliados. Dados esses que estão de acordo com estudo de Pflanzer et al. (2010), no qual se obteve índices satisfatórios de intenção de compra na avaliação da bebida láctea achocolatada. 
Elaboração de bebida láctea fermentada com diferentes tipos de polpas de frutas

Diante dos resultados obtidos, observa-se que o desenvolvimento de produtos utilizando o soro de queijo é bastante promissor, pois as bebidas lácteas fermentadas são uma realidade no mercado brasileiro, porque já representam $25 \%$ do mercado total de iogurtes no país
(Pflanzer et al., 2010). Vale destacar ainda que a produção de derivados do leite é uma tendência, e a indústria deve se adequar à realidade de que a população consumidora detém conhecimentos e identificam o importante valor nutricional desses alimentos (Oliveira et al., 2010).

Figura 2 - Teste de intenção de compra das bebidas lácteas fermentadas nos sabores goiaba, maracujá, seriguela e coquinho-azedo. $(n=200)$.

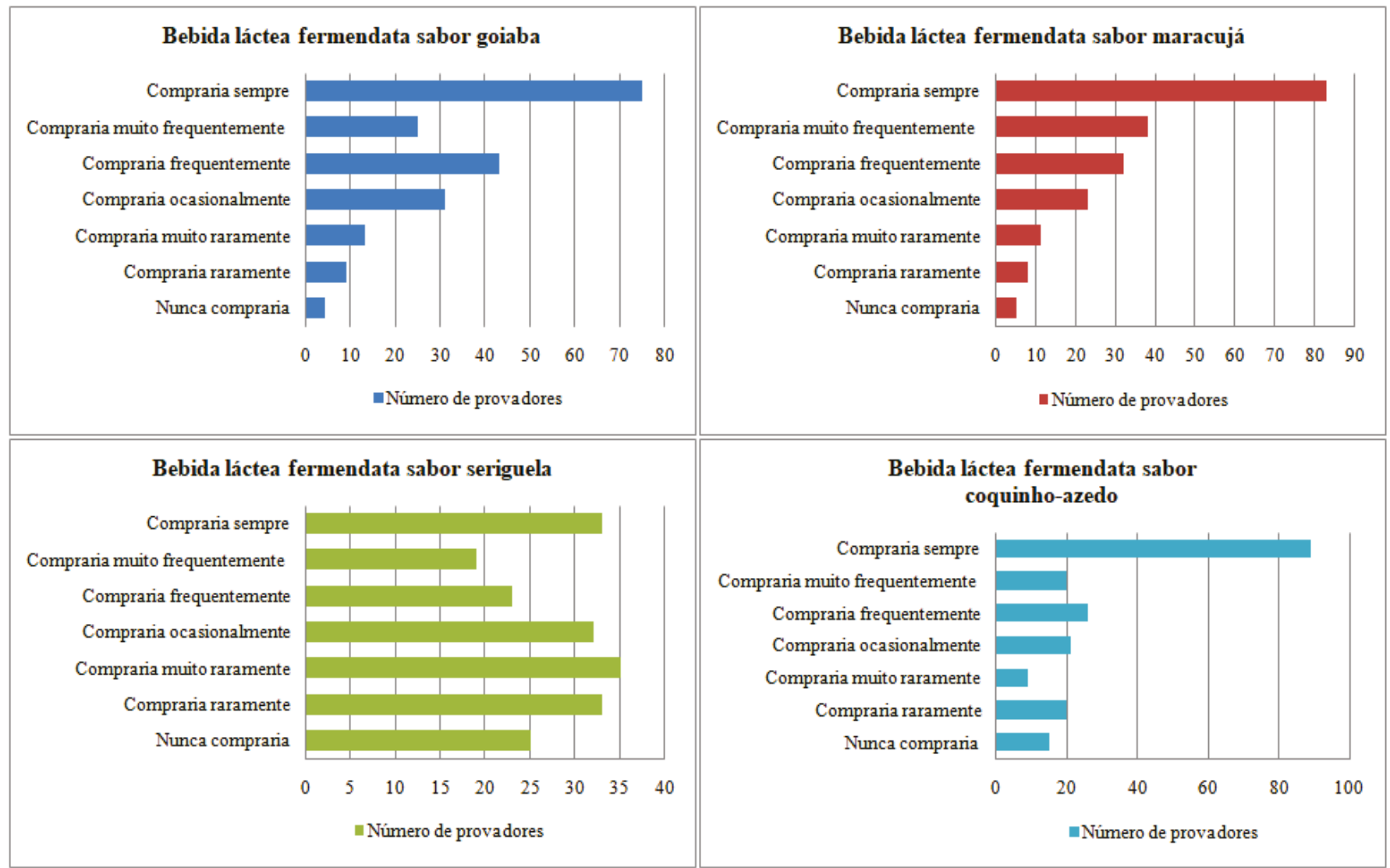

Fonte: próprios autores (2020).

A elaboração de bebidas lácteas fermentadas a base de polpas de frutas do cerrado e soro de leite tende a ser de grande valia para o mercado alimentício, pois além de possuir um alto valor nutricional presente na composição, o produto também é de baixo custo financeiro, tornando-se acessível a todos os públicos. O desenvolvimento deste produto visa contribuir com a preservação do meio ambiente através do reaproveitamento do soro que derivado de outros processos lácteos e evitando assim que o mesmo seja descartado diretamente no solo, objetiva-se também introduzir no mercado os frutos nativos que são ótimas fontes de nutriente, mas que são pouco aproveitados pela indústria.

\section{Conclusão}

As análises realizadas permitiram concluir que os objetivos propostos pelo trabalho foram atingidos, tanto no que diz respeito às análises microbiológica, pois as mesmas apresentaram resultados satisfatórios, quanto em relação à boa aceitabilidade do produto. Com os resultados obtidos na análise sensorial é notável a boa aceitabilidade do produto testado, observando algumas perspectivas de melhoria para trabalhos futuros. Esperase que este alimento traga benefícios tecnológicos e nutricionais a partir de constituintes nutritivos e de baixo custo, pois além de incentivar a valorização dos frutos nativos do cerrado e o reaproveitamento do soro do leite, pretende-se ofertar um produto que traga benefícios á saúde e economia a população. 


\section{Referências}

Aguiar M. C. S.; Silvério, F. O.; Pinho, G. P.; Lopes, P. S. N.; Fidêncio, P. H.; Ventura, S. J. 2014. Volatile compounds from fruits of Butia capitata at different stages of maturity and storage. Food Research International, 62: 1095-1099. Doi: https://doi.org/10.1016/j.foodres.2014.05.039.

Arshadi, M,; Foroughifard, S.; Etemad, G. J.; Abbaspourrad, A. 2015. Preparation of iron nanoparticles-loaded Spondias purpurea seed waste as an excellent adsorbent for removal of phosphate from synthetic and natural waters. The Journal of Colloid and Interface Science, 452(15): 69-77. Doi: doi: 10.1016/j.jcis.2015.04.019.

Baldissera, A. C.; Betta, F. D.; Penna, A. L.; Lindner, J. D. 2011. Alimentos funcionais: uma nova fronteira para o desenvolvimento de bebidas protéicas a base de soro de leite. Semina: Ciências Agrárias, 32(4): 1497-1512. Disponível em: https://www.redalyc.org/articulo. oa?id $=445744110040$.

Batista, M. A.; Gama, L. L. A.; Almeida, L. P; Ornellas, C. B. D.; Santos, L. C.; Cruz, L. L.; Silvestre, M. P. C. 2015. Desenvolvimento, caracterização e análise sensorial de formulações alimentares com proteínas do soro de leite ou albumina para crianças. Brazilian Journal of Food Technology, 18(1): 31-41. Doi: https://doi.org/10.1590/1981-6723.3214.

Brasil. Ministério da Agricultura, Pecuária e Abastecimento. Plano mais pecuária. Assessoria de Gestão Estratégica. - Brasília: MAPA/ACS, 2014. 32 p. Disponível em: https://www.agricultura.go.gov.br/files/ docs/pecuaria/mais_pecuaria.pdf.

Brasil. Ministério da Agricultura, Pecuária e Abastecimento. Instrução Normativa no 46 de 23/10/2007. Adota o Regulamento Técnico de Identidade e Qualidade de Leites Fermentados. 2007. Dísponivel em: https://freitag.com.br/files/uploads/2018/02/portaria_norma_354.pdf.

Brasil. Ministério da Agricultura Pecuária e Abastecimento. Instrução Normativa no 62, 26 de agosto de 2003. Oficializa os Métodos Analíticos Oficiais para Análises Microbiológicas para Controle de Produtos de Origem Animal e Água. Diário Oficial da União, Brasília, DF, 26 de agosto de 2003. Disponível em: https://www.defesa.agricultura.sp.gov. br/legislacoes/instrucao-normativa-sda-62-de-26-08-2003,665.html.

Desconsi, A. C.; Izario Filho, H. J.; Salazar, R. F. S. 2014. Avaliação físico-química e microbiológica do soro de leite concentrado obtido por osmose inversa. Revista Ambiente \& Água, 9(2): 325-335. Doi: https://doi.org/10.4136/ambi-agua.1316.

Engels, C.; Gräter, D.; Esquivel, P. Jiménez, V. M.; Gänzle, M. G.; Schieber, A. 2012. Characterization of phenolic compounds in jocote (Spondias purpurea L.) peels by ultrahigh performance liquid chromatography/ electrospray ionization mass spectrometry. Food Research International, 46(2): 557-562. Doi: https://doi.org/10.1016/j.foodres.2011.04.003.

Farias, P. K. S. Elaboração de bebida láctea fermentada com adição de óleo essencial. Montes Claros, MG. Instituto de Ciências Agrárias/ UFMG, 2016. $67 \mathrm{f}$.

Ferrari, A. S.; Baldoni, N. R.; Azeredo, E. M. C. 2013. Análise sensorial e físico-química de produtos elaborados à base de soro de leite. Revista da Universidade do Vale Rio Verde, 10(1): 216-223. Doi: http://dx.doi. org/10.5892/ruvrv.2013.111.216223.
Flores, G.; Wu, S. B.; Negrina, A.; Kennelly, E. J. 2013. Chemical composition and antioxidant activity of seven cultivars of guava (Psidium guajava) fruits. Food Chemestry, 170(1): 327-335. Doi: 10.1016/j. foodchem.2014.08.076.

Instituto Brasileiro de Geografia e Estatística - IBGE. Indicadores IBGE - Estatística da Produção Pecuária. Brasília, p. 83, 2018. Disponível em: https://biblioteca.ibge.gov.br/visualizacao/periodicos/2380/ epp_2018_4tri.pdf.

Instituto Adolfo Lutz. Normas Analíticas do Instituto Adolfo Lutz: Métodos Físico-químicos para Análise de Alimentos. 4⿳ạa edição, 1a edição Digital, São Paulo: Instituto Adolpho Lutz, 2008. 1020 p. Disponível em: https://wp.ufpel.edu.br/nutricaobromatologia/files/2013/07/ NormasADOLFOLUTZ.pdf.

Kempka, A. P.; Krüger, R. L.; Valduga, E.; Di Luccio, M.; Treichel, H.; Cansian, R,.; Oliveira, D. 2008. Formulação de bebida láctea fermentada sabor pêssego utilizando substratos alternativos e cultura probiótica. Ciência e Tecnologia dos Alimentos, 28(1): 170-177. Doi: https://doi. org/10.1590/S0101-20612008000500027.

Luiz, L. M. P; Rocha, J. C. G.; Sá, J. P. N.; Brandão, S. C. C.; Araújo, E. A.; Carvalho, A. F. 2014. Conservação à temperatura ambiente de uma bebida a base de soro de leite envasada a quente. Ciência Rural, 44(11): 2090-2094. Doi: https://doi.org/10.1590/0103-8478cr20130647.

Oliveira, D. F.; Bravo, C. E. C.; Tonial, I. B. 2012. Soro de leite: um subproduto valioso. Revista do Instituto de Laticínios Cândido Tostes, 67(385): 64-71. Disponível em: https://www.revistadoilct.com.br/ rilct/article/view/215/223.

Oliveira, J. P. F; Barreto, M. L. J.; Medeiros, H. R.; Marques Júnior, S.; Rangel, A. H. N. 2010. Aspectos da comercialização de derivados lácteos em supermercados, padarias e lojas de conveniência do setor varejista de Natal/RN. Rama, Rev. Agronegócio Meio Ambiente, 3(3): 197-212. Doi: https://doi.org/10.17765/2176-9168.2010v3n3p\%25p.

Pflanzer, S. B.; Cruz, A. G.; Hatanaka, C. L.; Mamede, P. L.; Cadena, R.; Faria, J. A. F.; Silva M. A. A. P. 2010. Perfil sensorial e aceitação de bebida láctea achocolatada. Ciência e Tecnologia dos Alimentos, 30(2): 391-398. Doi: https://doi.org/10.1590/S0101-20612010000200016.

Siqueira, A. M. O.; Machado, E. C. L.; Campos, T. S.; Siqueira, L. P.; Stamford, T. C. M.; Stanford, T. L. M. 2015. Características sensoriais e estabilidade de bebida láctea simbiótica com sabor graviola. Boletim do Centro de Pesquisa e Processamento de Alimentos, 33(2): 19-30. Doi: http://dx.doi.org/10.5380/cep.v33i2.47234.

Siqueira, A. M. O.; Machado, E. C. L.; Stamford, T. L. M. 2013. Bebidas lácteas com soro de queijo e frutas. Ciência Rural, 43(9): 1693-1700. Doi: https://doi.org/10.1590/S0103-84782013000900025.

Storck, L.; Lúcio, A. D’C.; Krause, W.; Araújo, D. V.; Silva, C. 2014. Scaling the number of plants per plot and number of plots per genotype of yellow passion fruit plants. Acta Scientiarum. Agronomy, 36(1): 73-78. Doi: https://doi.org/10.4025/actasciagron.v36i1.17697.

Zoellner, S. S.; Cruz, A. G.; Faria, J. A. F; Bolini, H. M. A.; Moura, M. R. L.; Carvalho, L. M. J.; Sant'ana, A. S. 2009. Whey beverage with açai pulp as a food carrier of probiotic bacteria. Australian Journal of Dairy Technology, 64(2): 165-169. Disponível em: https://www.cabdirect. org/cabdirect/abstract/20103024420. 